\title{
Thoracic outlet syndrome causing epidural hematoma: case illustration
}

\author{
*Nicolas Mélé, MD, ${ }^{1,5,6}$ Grégoire Boulouis, MD, MSc, FESO,, 2,5,6 Eric Bozier, BS, ${ }^{3,5,6}$ \\ Abderrazak Akhrouf, MD, ${ }^{4-6}$ and Johan Pallud, MD, PhD 35,5 \\ Departments of ${ }^{1}$ Neurology, ${ }^{2}$ Neuroradiology, ${ }^{3}$ Neurosurgery, and ${ }^{4}$ Anesthesiology, Sainte-Anne Hospital, Paris; \\ ${ }^{5}$ Paris Descartes University, Sorbonne Paris Cité, Paris; and ${ }^{6}$ INSERM, UMR1266, Centre Psychiatrie et \\ Neurosciences, Paris, France \\ https://thejns.org/doi/abs/10.3171/2019.12.JNS192397
}

KEYWORDS thoracic outlet syndrome; subclavian vein; epidural hematoma; peripheral nerve

$\mathrm{F}$ OLLOWING a 3-hour-long tennis session, a 31-year-old right-handed man with no significant past medical history presented with rapidly progressive paraplegia. Clinical examination showed T6 hypotonic paraplegia, severe sensory deficit (both superficial and deep sensibility), and urine retention. Spine MRI showed an acute epidural hematoma at the T3-4 levels (Fig. 1A). CT angiography fortuitously revealed right-sided venous thoracic outlet syndrome (Fig. 1B-D). Emergency thoracic laminectomy allowed evacuation of the hematoma and coagulation of the epidural veins. At postoperative day 1 , the patient had recovered. The thoracic outlet syndrome was managed a few weeks later by thoracic surgical intervention. Six months thereafter, clinical examination was normal. Chronic venous compression, therein caused by venous thoracic outlet syndrome responsible for an epidural venous reflux, should be considered as a possible etiology of spontaneous acute thoracic epidural hematoma.

\section{Disclosures}

The authors report no conflict of interest.

\section{Author Contributions}

Drafting the article: Mélé, Pallud. Critically revising the article: Boulouis, Pallud. Reviewed submitted version of manuscript: all authors. Approved the final version of the manuscript on behalf of all authors: Mélé. Administrative/technical/material support: Boulouis. Study supervision: Mélé. 
Mélé et al.
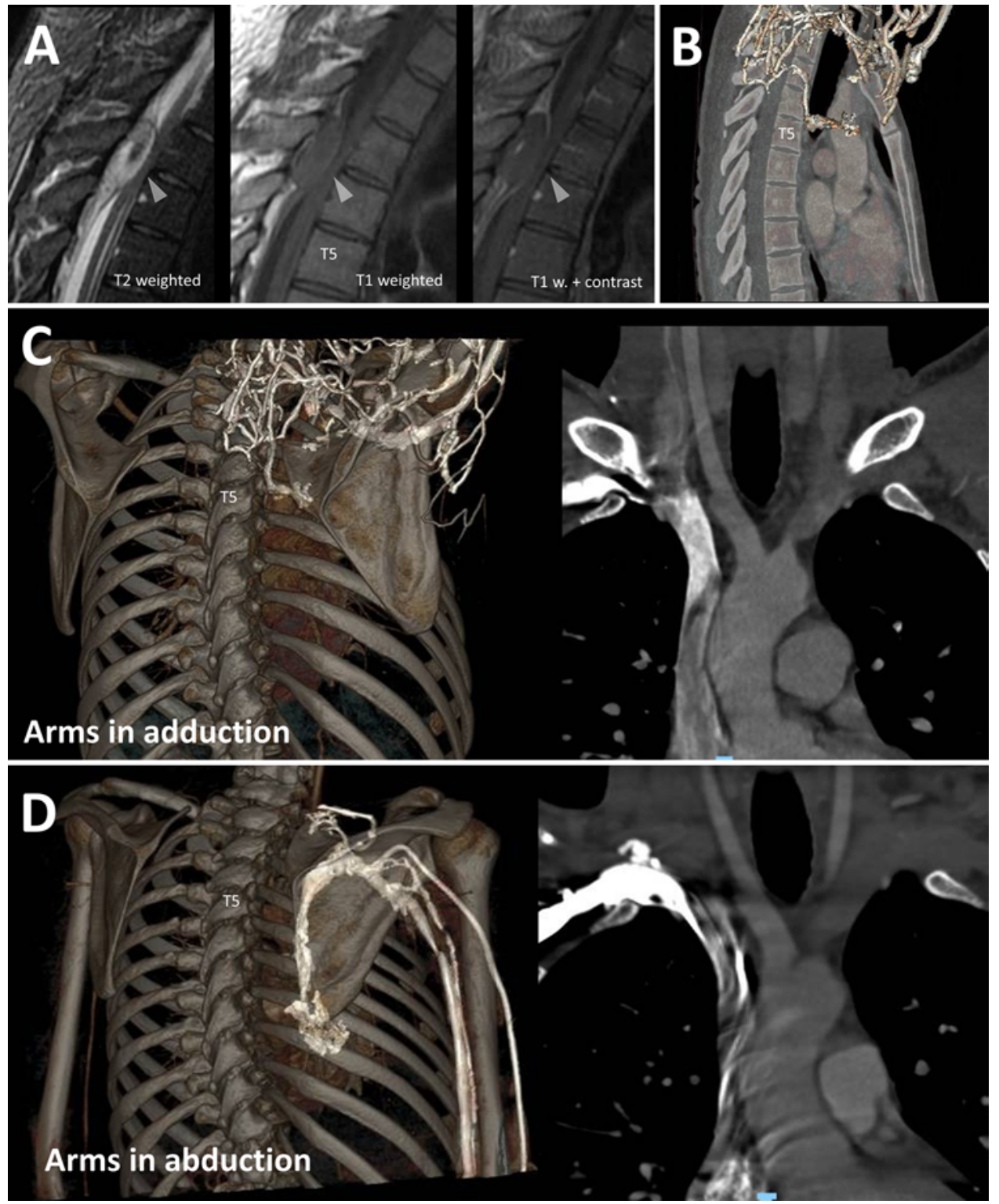

FIG. 1. Preoperative MR images (A) demonstrating an acute T3-4 epidural hematoma. CT angiography (B) demonstrating a positional venous thoracic outlet syndrome. The abducted arm induced a right subclavian vein obstruction with permeation of anastomotic veins, including epidural veins and the superior azygos vein, to reach the superior vena cava (C), which resolved with arm repositioning (D). Figure is available in color online only. 